\title{
Factors Affecting Employee Retention in Zimbabwean Companies
}

\author{
Gibbet Murambiwa Magaisa, Aldersgate University, South Africa \\ Austin Musundire, University of South Africa, South Africa
}

\begin{abstract}
The decline of the Zimbabwean economy characterised by the high inflation rate has rendered it difficult for Zimbabwean manufacturing to retain talented employees. The quantitative research methodology was adopted in this paper. The sample size of the study comprised 100 respondents who were randomly selected from the manufacturing companies in Zimbabwe. The sample size of the study was made out of 10 managing directors, 10 managers, 10 supervisors, and 70 employees drawn from the 50 manufacturing companies that were randomly selected. It was established that the companies are failing to retain talented employees, and a lot of the employees are leaving the organisations. Retrenchments and restructurings have become the order of the day. The study recommended that employees needed to implement employee retention strategies to remain viable.
\end{abstract}

\section{KEYWORDS}

Deindustrialisation, Employee Retention, Employee Turnover, Involuntary Turnover, Retrenchment, Skilled Workforce, Talent Management, Talented Employees, Voluntary Turnover

\section{BACKGROUND TO THE STUDY}

The structure of this paper starts with the background to the study which highlights and puts the perspective of the problem that is at hand. The literature review then follows, giving the essence of the subject under study; this is followed by the research methodology which shows how the study was carried out. The analysis and discussions of results in relation to the literature review then come next, followed by the recommendations and conclusions.

The performance of an organisation is mainly hinged upon its ability to meet the organisational set objectives. For this to be achieved, it is however, imperative that the organisation retains its employees. A well-coordinated and motivated workforce can lead to the achievement of organisational objectives. Employees are the life line of an organisation, retaining them is however, a great challenge which organisations face (Kossivi, Xu \& Kalgora, 2016). Employee retention has to be achieved if an organisation needs to meet its expected operational targets. It is essential for organisations to have suitable human resources policies and practices in place; if they are to retain talented and committed employees (Metha, Kurbetti \& Dhankhar, 2014). Organisations that retain talented employees have a competitive edge over their rivals since they are bound to raise their productivity levels (Azeez, 2017). Retention of employees increases the profitability of the organisation, shapes the market image and the reputation of the organisation. It helps to maintain employee retention as a planned and coordinated activity that the organisation takes in order to meet the needs of the employees with the view of retaining them (Shakeel \& But, 2015).

\section{DOI: 10.4018/IJAMTR.288507}

This article published as an Open Access article distributed under the terms of the Creative Commons Attribution License (http://creativecommons.org/licenses/by/4.0/) which permits unrestricted use, distribution, and production in any medium, provided the author of the original work and original publication source are properly credited. 


\section{LITERATURE REVIEW}

This section covers the review of related literature. The main literature that is covered in this paper incorporates Southern African Development Community manufacturing perspectives, Zimbabwean Manufacturing Industry, employee retention, employee turnover, talent management, job satisfaction, job satisfaction and employee retention strategies. This literature was selected since it covers the main factors which affected employee retention in organisations (James \& Mathew, 2012; Cloutier et al., 2015; Haider et al., 2015; Sutanto \& Kurniawan, 2016).

\subsection{Southern African Development Community (SADC) Manufacturing Perspective}

The Southern African Development Community (SADC) initiated an industrialisation strategy which is designed within the Industrial Development Policy Framework and this is aligned to the structural transformation theory (IFAD, 2016). The policy is targeted to foster intra-regional cooperation at the national level among the member states; to nurture a diversified, innovative and globally competitive industrial base. The solid industrial base is meant to contribute towards employment creation and shared regional economic growth. The success of the strategy is dependent upon the ability of the actors to harness the region's comparative advantages in natural resources and abundant labour force (Habiyaremye, 2020). The strategy was a noble initiative; however, the strategy has failed to produce the desired outcomes.

It is critical to have internal trade intensity within the SADC region in order to achieve the benefits of closer integration. The SADC trading bloc is completely different to the Asian and European trading blocs. The trade structure of SADC is mainly dominated by primary commodity exports and finished product imports. The production structure of SADC member states has relative similarities; with the exception of South Africa, eventually, there is little trade among the member states (Ngarachu et al., 2018).

Table 1 gives an oversight of manufacturing value-added share to the SADC gross domestic product (GDP) for member states for the period 2008 to 2018. The average share of the manufacturing value-added in the SADC region has remained in the 12 percent region for the 2008 to 2018 period; this is relatively lower than the averages that are found in other developing countries regional blocs outside the African continent. The East Asia and Pacific range is in the 29 percentile average of GDP (World Bank, 2019).

Table 2 reflects the dominant position occupied by South Africa in the intra SADC exports. South African goods and services account for $58 \%$ of the total SADC intra-regional exports. The market share of the next largest exporters, who are Angola and Namibia have respectively declined from 9 to 8 percent in 2008 and 6\% in 2019. Zimbabwe and DR Congo have gradually increased their exports over the last 10 years. Their current share is, however, one-eighth of South Africa's export share. Exports of South African manufactured goods dominate the trade flow of other SADC member states (SADC, 2019).

\subsection{Zimbabwean Manufacturing Sector}

The Zimbabwean manufacturing sector is still struggling due to the multi-currency system which was introduced in February 2009 (Mazhindu, 2014). Inadequate funding has negatively affected the acquisition of machinery and technology required for production purposes (CZI, 2016). There has been instability in the Gross Domestic Product (GDP) growth, it increased from $5.4 \%$ to $16.3 \%$ in 2009, declined to $0.6 \%$ in 2016 and increased to $3.7 \%$ in 2017 (RBZ, 2017), it, however, remained at $3.7 \%$ in 2018 (World Bank, 2018). Capacity utilisation in the sector declined to $36.4 \%$ in 2019 from, $48 \%$ in 2018. The 2020 capacity utilisation is projected at $27 \%$ (CZI, 2020).

Massive deindustrialisation, closure of firms and downsizing negatively affected the Zimbabwean manufacturing sector. It is worth noting that of the seventy manufacturing firms listed on the stock exchange, only four are operating at 50\% capacity level (CZI, 2013). The manufacturing sector is 
Table 1. Share of manufacturing value added to total GDP in SADC countries

\begin{tabular}{|l|l|l|l|l|l|l|l|l|l|l|l|}
\hline \multicolumn{1}{|c|}{$\begin{array}{c}\text { SADC } \\
\text { MEMBER }\end{array}$} & $\mathbf{2 0 0 8}$ & $\mathbf{2 0 0 9}$ & $\mathbf{2 0 1 0}$ & $\mathbf{2 0 1 1}$ & $\mathbf{2 0 1 2}$ & $\mathbf{2 0 1 3}$ & $\mathbf{2 0 1 4}$ & $\mathbf{2 0 1 5}$ & $\mathbf{2 0 1 6}$ & $\mathbf{2 0 1 7}$ & $\mathbf{2 0 1 8}$ \\
\hline Angola & 3.5 & 5.2 & 4.6 & 4.2 & 4.3 & 4.8 & 5.2 & 5.1 & 5.0 & 5.0 & 7.4 \\
\hline Botswana & 6.4 & 7.2 & 7.1 & 6.4 & 6.6 & 6.4 & 5.8 & 6.4 & 5.7 & 5.6 & 5.7 \\
\hline Comoros & 7.4 & 7.7 & 7.5 & 7.7 & 7.3 & 7.8 & 8.1 & 8.2 & 8.6 & 9.0 & 9.2 \\
\hline DR Congo & 23.2 & 26.5 & 17.0 & 16.2 & 16.4 & 16.6 & 16.7 & 17.7 & 20.4 & 20.8 & 18.8 \\
\hline Eswatini & 36.1 & 36.3 & 34.0 & 33.3 & 33.4 & 31.8 & 32.9 & 34.0 & 32.8 & 32.0 & 32.8 \\
\hline Lesotho & 21.1 & 17.5 & 13.2 & 13.1 & 12.1 & 11.8 & 11.4 & 12.5 & 12.0 & 12.1 & 14.5 \\
\hline Madagascar & 14.6 & 14.4 & 14.3 & 14.3 & 14.3 & 14.1 & 14.0 & 13.8 & 12.9 & 13.1 & 14.1 \\
\hline Malawi & 12.6 & 11.2 & 10.7 & 10.4 & 10.1 & 10.1 & 10.1 & 10.2 & 10.1 & 9.8 & 9.2 \\
\hline Mauritius & 17.2 & 16.7 & 15.9 & 15.7 & 15.5 & 15.7 & 15.3 & 14.7 & 14.0 & 13.4 & 12.9 \\
\hline Mozambique & 13.4 & 11.9 & 11.3 & 11.2 & 10.0 & 9.5 & 9.9 & 10.0 & 9.6 & 10.0 & 10.3 \\
\hline Namibia & 12.3 & 14.1 & 13.5 & 14.8 & 13.1 & 11.9 & 10.8 & 10.5 & 12.0 & 11.7 & 11.0 \\
\hline Seychelles & 10.8 & 9.2 & 9,7 & 9.4 & 10.3 & 8.6 & 7.9 & 7.2 & 7.0 & 7.4 & 7.9 \\
\hline South Africa & 16.0 & 15.0 & 14.4 & 13.3 & 13.0 & 12.9 & 13.4 & 13.4 & 13.5 & 13.4 & 13.2 \\
\hline Tanzania & 7.4 & 7.3 & 7.3 & 8.1 & 10.2 & 9.8 & 9.9 & 8.6 & 8.5 & 8.4 & 8,7 \\
\hline Zambia & 9.0 & 9.0 & 8.0 & 8.0 & 7.5 & 6.4 & 7.3 & 7.9 & 8.1 & 7.9 & 9.9 \\
\hline Zimbabwe & 15.9 & 12.5 & 10.4 & 10.3 & 15.8 & 14.4 & 13.9 & 13.2 & 12.8 & 12.1 & 13.3 \\
\hline SADC Total & 13.0 & 13.1 & 12.3 & 11.3 & 11.1 & 10.9 & 11.2 & 11.2 & 11.5 & 11.2 & 11.9 \\
\hline
\end{tabular}

Source: SADC (2019)

Table 2. Shares of total intra-SADC exports for largest exporters

\begin{tabular}{|c|c|c|c|c|c|c|c|c|c|c|c|}
\hline $\begin{array}{c}\text { SADC } \\
\text { MEMBER }\end{array}$ & 2008 & 2009 & 2010 & 2011 & 2012 & 2013 & 2014 & 2015 & 2016 & 2017 & 2018 \\
\hline Angola & $9 \%$ & $5 \%$ & $5 \%$ & $5 \%$ & $7 \%$ & $4 \%$ & $5 \%$ & $4 \%$ & $5 \%$ & $4 \%$ & $6 \%$ \\
\hline DR Congo & $2 \%$ & $2 \%$ & $8 \%$ & $3 \%$ & $3 \%$ & $4 \%$ & $5 \%$ & $6 \%$ & $6 \%$ & $6 \%$ & $6 \%$ \\
\hline Namibia & $8 \%$ & $11 \%$ & $8 \%$ & $7 \%$ & $5 \%$ & $7 \%$ & $6 \%$ & $7 \%$ & $6 \%$ & $6 \%$ & $6 \%$ \\
\hline South Africa & $60 \%$ & $60 \%$ & $57 \%$ & $59 \%$ & $55 \%$ & $54 \%$ & $55 \%$ & $53 \%$ & $54 \%$ & $57 \%$ & $58 \%$ \\
\hline Zimbabwe & $3 \%$ & $4 \%$ & $4 \%$ & $6 \%$ & $8 \%$ & $8 \%$ & $7 \%$ & $7 \%$ & $8 \%$ & $8 \%$ & $7 \%$ \\
\hline Rest of SADC & $23 \%$ & $23 \%$ & $30 \%$ & $30 \%$ & $32 \%$ & $35 \%$ & $34 \%$ & $36 \%$ & $35 \%$ & $33 \%$ & $29 \%$ \\
\hline $\begin{array}{l}\text { Total Initial } \\
\text { SADC Export } \\
\text { (US\$ Million }\end{array}$ & $\begin{array}{l}26 \\
378\end{array}$ & $\begin{array}{l}25 \\
856\end{array}$ & $\begin{array}{l}33 \\
135\end{array}$ & $\begin{array}{l}36 \\
958\end{array}$ & $\begin{array}{l}40 \\
613\end{array}$ & $\begin{array}{l}41 \\
843\end{array}$ & $\begin{array}{l}40 \\
783\end{array}$ & $\begin{array}{l}35 \\
395\end{array}$ & $\begin{array}{l}34 \\
371\end{array}$ & $\begin{array}{l}35 \\
316\end{array}$ & $\begin{array}{l}37 \\
156\end{array}$ \\
\hline
\end{tabular}

Source: SADC (2019) 
heavily affected by a plethora of challenges such as the use of obsolete equipment, inconsistent supply of water, electricity, supply of raw materials, research and development, working capital, liquidity challenges, poor road and rail infrastructure, lack of infrastructure and competition from imports (Zimwara \& Mbohwa, 2015, p.155). It is evident that the manufacturing sector in Zimbabwe has been underperforming for a long period. This has naturally affected employee retention. The status quo has forced skilled employees to look for alternative employment within the region.

Manufacturing companies in Zimbabwe are confronted with a multitude of challenges which include: challenges faced in the manufacturing plant and business challenges. Challenges experienced at the plant include the use of old equipment; an erratic supply of electricity; an erratic supply of water; raw material supply; lack of investment in research and development; lack of specialized skills; and shortages of spare parts for machinery. Business challenges include low demand for some products, high labour costs, lack of working capital, high utility bills, liquidity challenges in the market and competition from imports (Zimwara \& Mbohwa 2015, p.155; CZI, 2015. p.6).

There is a serious shortage of skilled manpower in South Africa. The South African and international organisations are competing for talented and skilled employees. The South African development and socio-economic growth are severely affected by lack of skilled and talented employees (Rasool \& Botha, 2011; Muteswa \& Ortlepp, 2011). There is an influx of the Zimbabwean skilled workforce who is absorbed into the South African labour market since the manufacturing sector in South Africa is highly in need of skilled and talented manpower.

\subsection{Employee Retention}

The performance of an organisation is mainly hinged upon its ability to meet the organisational set objectives. For this to be achieved, it is, however, imperative that the organisations retain their employees. A well-coordinated and motivated workforce can lead to the achievement of organisational objectives. Employees are the lifeline of an organisation, retaining them is however, a great challenge that institutions face. Organisations need to have suitable human resources policies and practices in place; if they are to retain talented and committed employees (Metha, Kurbetti \& Dhankhar, 2014). Organisations that retain talented employees have a competitive edge over their rivals since they are bound to raise their productivity levels (Azeez, 2017). Retention of employees increases the profitability of the organisation, shapes the market image and the reputation of the organisation. Employee retention is a planned and coordinated activity that the organisation takes in order to meet the needs of the employees with the view of retaining them (Shakeel \& But, 2015).

\subsection{Employee Turnover}

Employee turnover is the ratio obtained by dividing the number of employees who left the organisation over a given period, by the number of employees in that organisation over the given period (Ongori, 2007). Employee turnover has a negative effect due to the costs that an organisation has to incur to replace and train the new employee who replaces the one that will have left the organisation. Induction and informal training of the employee has to be also considered. It takes time for the new employee to reach the required performance levels (Ongori, 2007). The Zimbabwean manufacturing sector is currently experiencing these challenges due to staff turnover, as employees are searching for greener pastures.

There are two types of employee turnover namely voluntary turnover and involuntary turnover. Voluntary turnover takes place when an employee decides to terminate his/her employment contract with the organisation. Involuntary turnover takes place when the organisation terminates the employee's contract by retrenching the employee (Zhang, 2016). Employee turnover disturbs organisational processes and causes undue stress to the remaining employees, as they try to cope with the increased workload (Rijamampianina, 2015). Employee turnover creates unplanned costs related to the recruitment and training of replacement employees and is also a threat to organisational growth and productivity (Rijamampianina, 2015; Akinyomi, 2016). 
Figure 1. The talent formula

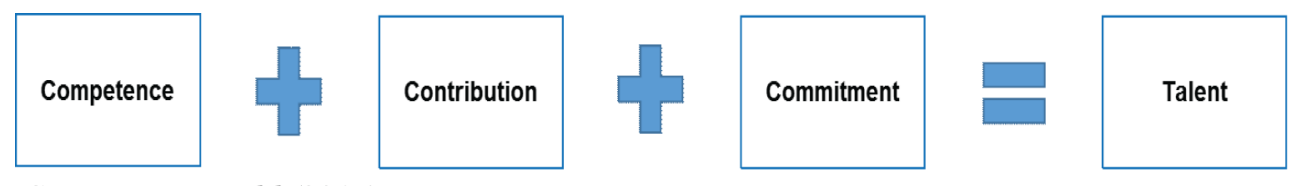

Source: Fitzgerald (2014)

A study by Arokiasamy postulates that for an organisation to be successful in highly competitive global environments, it has to comprehend the reasons behind employee turnover and try as much as possible to retain talented staff. High staff turnover is usually directed to the inability of the management to lead and manage the affairs of an organisation effectively. High levels of inefficiencies lead to high levels of staff turnover. The organisation is negatively affected as it loses experienced and talented manpower and will as a result fail to meet its organisational objectives (Arokiasamy, 2013).

\subsection{Talent Management}

Talent management is the ability to attract, develop, manage and retain talented staff in an organisation. Talented individuals are critical in an organisation and have to be retained at all costs (Fitzgerald, 2014). Figure 1 illustrates the components that Fitzgerald (2014) proposed in order to come up with talent.

Strategic planning is one of the major tools that an organisation can put in place in order to ensure that it retains skilled and talented employees. A strategic human resource base needs to be considered in strategic plans to ascertain that there is room to attract, develop, manage and retain talent. There is a need for the Zimbabwean manufacturing industry to ensure that they put strategies and mechanisms in place, in order to increase productivity and retain the talented employees they have.

\subsection{Job Satisfaction}

The efficiency productivity levels of an organisation are determined by the level at which the employees are satisfied with their jobs. A positive feeling towards one's job increases productivity as opposed to negative feelings which result in low productivity and results in the organisation failing to meet its organisational objectives (Jalagat, 2016). Satisfied employees tend to be highly productive, unlike employees that are dissatisfied who tend to be less productive due to absenteeism (Singh and Jain, 2013). Highly satisfied employees are loyal to the organisation; they necessitate a pleasing working environment which results in a better working performance as employees work independently and are highly motivated (Dalluay, Jalagat, Zadjali \& Al-Abdullah, 2017). Motivation is defined as "A set of energetic forces that originate both within as well as beyond an individual's being to initiate work-related behaviour and to determine its form, direction, intensity and duration" or "the process that accounts for an individual's intensity, direction and persistence of effort toward attaining a goal" (Woods \& West, 2015:121).

Lack of job satisfaction due to underperformance of the industry has resulted in employee turnover. The industry has, however, failed to keep its skilled personnel and talent resulting in employees leaving for the thriving South African labour market. There is a lot of work and investment that needs to be done in order to bring the Zimbabwean manufacturing sector to competitive levels.

\subsubsection{Job Satisfaction and Employee Retention}

Studies carried out indicate that employees are motivated if they work under acceptable working conditions, as well as a satisfying working atmosphere, realistic compensation and reasonable working conditions. The employees will match the employer's offer by excelling beyond the expected in order to achieve organisational objectives (Ul-Aabdeen, Khan, Tahir, Salman, Khan \& Ali, 2016). Job satisfaction drives employees to achieve much more beyond expectations. Employees' good behaviour 
towards work is shaped by job satisfaction. Production delays, absenteeism and turnover are usually triggered when the employees are not satisfied at work (Sila \& Sirok, 2018).

The factors which lead to employee job satisfaction are: a good working environment, effective and efficient leadership, attractive remuneration, fringe benefits, job fit and career development. Employees become committed to their work and the organisation if these factors are addressed ( $\mathrm{Al}$ Mamun \& Hassan, 2017).

\subsubsection{Management}

Employees do not stay in an organisation when management lacks adequate leadership skills to support, guide and motivate the employees. Management should provide performance feedback to the employees for them to improve. Employees need to see organised stable management that is capable to coach and training them (Al Mamun \& Hasan, 2017). The support that employees receive from their managers and supervisors is highly critical towards the retention of the employees. A strong bond of the relationship shared by the manager and the employee encourages the retention of the employee. A transparent relationship between the employee, supervisor and employer enhances the performance of the employee. It encourages the employee to be much more engaged and develops the skills and competency levels (Nasir \& Mahmood, 2018).

When an employee is coached and mentored by the line manager in a positive manner, it generates skills development for the employee, loyalty to the manager and creates an intention for the employee to want to remain with the organisation (Nwokocha \& Iheriohanma, 2012). A good manager-employee relationship is very critical as one of the major reasons that cause employees to leave the organisation is the behaviour of the manager (Nelms \& Bearden, 2018).

Poor management has a negative impact on organisational stability, as it leads to high staff turnover. Managers need to know how to supervise and motivate their staff. It is highly essential to empower employees by giving them decision-making responsibilities for them to be satisfied in their positions. Empowered employees would always be committed to remaining in the organisation and this reduces staff turnover (Zhang, 2016).

The liquidity factors that affected the Zimbabwean manufacturing industries have made it difficult for managers to plan and manage. Despite the efforts that management put in to sustain their organisations it has apparently become difficult to maintain high productivity and retain skilled personnel.

\subsubsection{Training and Development}

Employee training and development plays an important role in the improvement of employees' skills and talents for current and future positions. For organisations to survive under technological changes and stiff competition challenges they need to train and develop their employees in tandem with current trends (Salah, 2016; Metha et al., 2014). The career growth of the employees is pinned upon training and development, hence the employees would need training and development opportunities for them to enhance their career development opportunities (Ldama \& Bazza, 2015).Employees training and development enhances employee retention of individuals that seek career advancement in their jobs, as individuals are enthusiastic to acquire new skills and get to acquire new skills in order to get more responsibilities at the workplace (Chen, 2014). Comprehensive training and development is a strategy that employers can use to improve employee productivity (Oki, 2014).

\subsubsection{Rewards and Recognition}

Employee recognition is a return that is awarded to employees in order to retain them for their achievements of producing the desired results at work. Monetary rewards or verbal recognitions can be given to the employees by the managers. Rewards and recognitions are used in order to avoid the dissatisfaction of employees which will encourage them to leave the organisation (Mngomezulu, Challenor, Munapo, Mashau \& Chikandiwa, 2015). Employees can be retained by giving them 
monetary rewards in the form of cash and allowances or it can be non-monetary recognition in the form of letters of appreciation (Nasir \& Mahmood, 2018).

Human resources practitioners are of the view that rewards and recognition are highly effective towards the motivation of the employees at the workplace. They also strongly agree that rewards and recognition positively affect productivity levels, return on investment, cost-control measures and enhance the sustainability of the organisation (SHRM \& Globoforce, 2018). Employee recognition is a very powerful strategy that motivates and retains employees in an organisation. A good rewarding and recognition system motivates the employees (Cheema, Shujaat \& Alam, 2013). Rewards and recognition increase the morale of the employees, self-esteem, well-being and are relevant strategies that organisations can use to avert staff turnover (Naseebullah \& Ahmad Shahrul Nizam, 2017).

In the Zimbabwean manufacturing sector context it is extremely difficult to reward and recognise employees due to unavailability of the resources. Retaining employees under these circumstances has proven to be very difficult.

\subsubsection{Remuneration}

A study carried out by Calvin specifies that financial benefit that employees receive in exchange for their services at work in the form of salaries, wages, bonuses, incentives, allowances and other benefits that are given by the employer is referred to as remuneration. Fair remuneration encourages the employees to remain at their organisation. Employees regard their remuneration to be fair when it is related to the market values of the same jobs in the industry (Calvin, 2017). Some people resign from their jobs due to unsatisfactory compensating systems. Misaligned pay structures cause employee turnover. The compensation levels have an effect on staff retention in organisations (Bryant \& Allen, 2013).

Remuneration has a strong bearing towards attracting and retaining the services of talented employees. Rewards are usually tied up to an individual performance in order to ascertain the increased production levels and also to ensure that talented employees are retained in the organisation (Adeoye \& Fields, 2014). Employees are flocking to the South African labour market due to unsatisfactory remuneration which the skilled and talented employees are getting as a result of the low productivity challenges which the sector is facing in Zimbabwe.

\subsubsection{Work-Life Balance}

Work-life balance is the ability of the employee to balance work, everyday life, social life, health and family, and it has become of great concern to the employer and the employee (Balamurugan \& Pasupathi, 2018). It can also be referred to as the equilibrium that exists between one's job and one's personal life (Bajpai, Prasad \& Pandey, 2016). Work-life balance is one of the major factors that contribute to employees wanting to leave the organisation (Maharan et al., 2018). Work-life balance is linked to an individual's performance, productivity and job satisfaction. A supportive work-life balance encourages a healthy work environment and balanced personal life, and this encourages employees to be loyal to the organisation they are working for (Garg \& Yajurvedi. 2016).

The work-life balance in the Zimbabwean manufacturing sector does not encourage a healthy work environment and balanced personal life. It does not support employee loyalty; as a result, an organisational culture entails attitudes, habits and values that give an organisation the competitive edge. Culture plays a critical role in employee job satisfaction (Kwakye, 2018).

An organisation with cultural issues, where management does not acknowledge its employees, is likely to face a high employee turnover as the employees would be propelled to leave the organisation because of the attitude that the leadership has towards the organisation's employees and organisational processes (Iqbal, Guohao \& Akhtar, 2017). Organisational culture is ultimately the views of the employees regarding the organisation. This is all about how the employees see the organisation (Uitzinger, Chrysler-fox \& Thomas, 2018). Management in the Zimbabwean manufacturing sector 
has little to offer due to the precarious Zimbabwean economic conditions. High employee turnover is rife as the management in the sector do not have much to offer to the employees.

\subsubsection{Innovation}

The development of new ideas, products and systems is highly essential in business and this is referred to as innovation. Businesses find it very difficult to retain generation Y employees (Aruna \& Anitha, 2015). Generation Y employees are those born between 1980 and 2000. They are also called millennials. They tend to be much more educated. Generation Y employees follow Generation X employees born between 1964 and 1980 and are known as baby boomers. Most of them hold middle and senior management and are close to retirement (Wong and Chin, 2016). Generation Y employees have a quick fix attitude, they need quick results. They are versatile in technology and they apply their technological expertise at their work environment. They tend to be frustrated by old technological systems (Aruna \& Anitha, 2016).

Innovation influences the performance of the employees. Innovation comes through the implementation of employees' ideas concerning the development and improvement of new products and services. This will help to improve the organisation's competitive edge, administration processes, technological innovativeness and effective performance to enhance higher productivity (Osman, Shariff \& Lajin, 2016). Although change is imminent and is good, there are some employees who resist change. There is also a need to allow the Generation $\mathrm{X}$ employees to develop themselves and be abreast with the advanced technological changes (Kesen, 2016). Under the current Zimbabwean manufacturing prevailing situation, innovation is needed in order to address the current scenario. Employees' ideas should also be incorporated in order to address the challenges that the sector is facing.

\subsubsection{Succession Planning}

Studies reflected that succession planning is a systematic endeavour by an organisation to ensure that leadership in a strategic key position is mentored and developed for the sake of continuity. This encourages staff retention and intellectual development of key personnel. Individual advancement is also achieved. Maintenance and preservation of the knowledge capital base are achieved in the organisation (Maphisa, Zwane \& Nyide, 2017). Individuals become motivated and excel at work when they are aware that the organisation has plans for them. The idea of leaving the organisation will be out of the employees' mind. They will, however, be loyal and perform well and this encourages them to be satisfied with their jobs resulting in effective employee retention (Maphisa, Zwane \& Nyide, 2017).

\subsubsection{Communication}

Employees need to be informed about the activities taking place within the organisation. Effective frequent communication should be promoted in order to keep the employees well-versed about the decisions that the organisation is taking and on other issues that directly affect them. Effective communication facilitates trust, frankness and helps the employees to identify with the organisation. Communication pertaining to the organisation and communication between strategic business units and management has a strong effect on employee retention. Employees' loyalty increases when employees become a part of the organisation's decision making processes (Dutta \& Banerjee, 2014).

Communication plays a critical role towards human resources management and in successfully leading the organisation. Insufficient communication triggers negative opinions within the employees and this will result in a lack of work commitment, demotivation and employee turnover (Nwagbara, Oruh, Ugorji \& Ennsra, 2013). Effective communication between the manager and the employees results in implausible levels of employee retention. Management usually holds frequent meetings with staff members, where the employer updates the employees with current events and situations that the organisation is facing. Some organisations practise an open-door teamwork policy that allows the employees to approach their manager to discuss their feelings and suggestions openly (Sandhya \& Kumar, 2011). 
Effective communication advances employees' identification with their organisation and nurtures an openness and trust culture (Kaur, 2017). Communication is regarded as the glue that bonds all the organisational activities, to bring synergy within the entire organisation. It has to be of high standard and relevant among all the stakeholders (Motlou, Singh \& Karodia, 2016). An organisation should have a transparent and clear-cut communication system and this eliminates job uncertainty and animosity with the culture of the organisation. Effective communication in organisations leads to collective commitment, employee engagement, collective commitment and employees will end up being satisfied with their jobs. This will eventually lead to a high level of employee retention (Newman, 2017).

\subsection{Employee Retention Strategies}

Studies on employee retention strategies need to be incorporated in the organisation's strategic plans if the organisation has to have effective retention strategies which are funded and supported by the leadership. Turnover must be managed and the reduction of turnover costs must be effectively managed. Employers must gather feedback from the employees pertaining to their preferences, expectations and intentions (Mahan et al., 2018).

Results from previous studies have reflected that for organisations to ensure that they retain employees and that employee satisfaction is high they have to respect the high performers accordingly, recognise the efforts of the high achievers and reward the high achievers with perks that will induce them to perform better (Mathimaran and Kumar, 2017). Employees need better working conditions, they need better working hours. They need to relax and work under relaxed conditions; frequent tea breaks and longer lunch breaks are proposed such that the workers will not be overworked. The employees should also be paid for their increased productivity levels. Incentives should be put in place to motivate the employees. Initiation of team work would help to increase performance and productivity as the employees would work as team members, and be able to consolidate their production levels to meet the organisational objectives (Mishra, 2013).

It has been observed in previous studies that the supervisor's attitude should be included as this has a strong bearing towards employee satisfaction and the retention of employees at work. Employee loyalty is determined by how satisfied the employees are with their employer. Employee and employer relationship needs to be improved. Measures have to be put in place to ascertain that good relationships are initiated, in order to facilitate the retention of the employees. There is also a need for the human resources department to come up with strategies in order to address the current market needs of the employees (Nasir \& Mahmood, 2018).

The organisations need to create stress free work environments to allow the employees to have a work-life balance atmosphere. This can be achieved by having weekend offs, working from home, job sharing as well as adjustment of working hours. Employees should be recognised and rewarded for their good performance (Balamurugan \& Abinaya, 2016).

\section{RESEARCH METHODOLOGY}

The quantitative research methodology was adopted in this paper. The sample size of the study comprised 100 respondents who were randomly selected from the manufacturing companies in Zimbabwe. The sample size of the study was made out of 10 Managing Directors, 10 Managers, 10 Supervisors and 70 employees drawn from the 50 manufacturing companies that were randomly selected. The closed-ended Likert Scale questionnaires were used to collect quantitative data. The Cronbach's Alpha was used to measure the reliability of the research instrument, which had a coefficient value of .97. The research instrument was very good and was meant to collect the data that it was supposed to collect. The quantitative data collected was analysed through the Statistical Programme for Social Sciences (SPSS). 


\section{BIOGRAPHICAL DATA}

\subsection{Age Group}

The results in Figure 2 indicated that $30 \%$ of the respondents were in the 25 to 31 years and below age group, $60 \%$ were in the 32 to 50 years age group and $10 \%$ of the respondents were in the 51 to 65 years age group. The majority of the respondents are still in the working-age group.

Figure 2. Age group

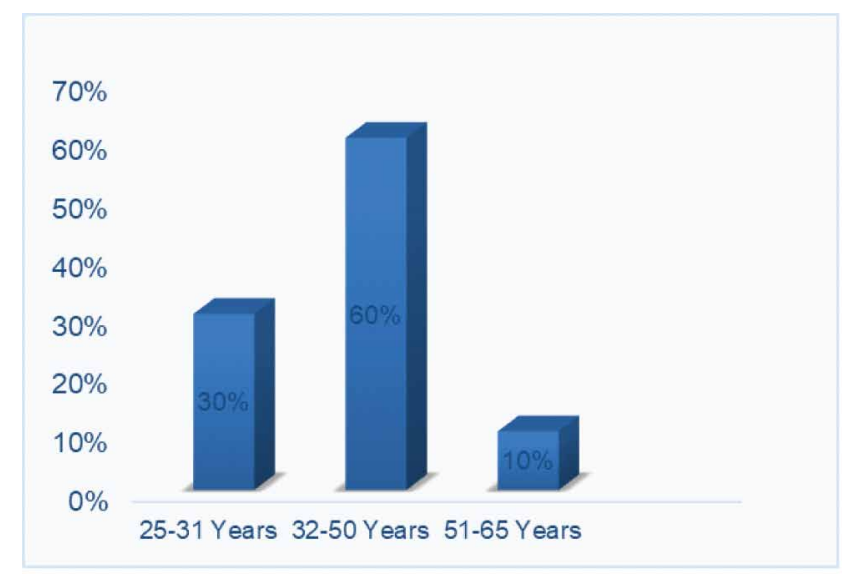

Source: Primary Data

\subsection{Gender of Respondents}

The results in Figure 3 indicated that $50 \%$ of the respondents were male and $50 \%$ were female. The results indicate that the respondents were equally represented.

Figure 3. Gender

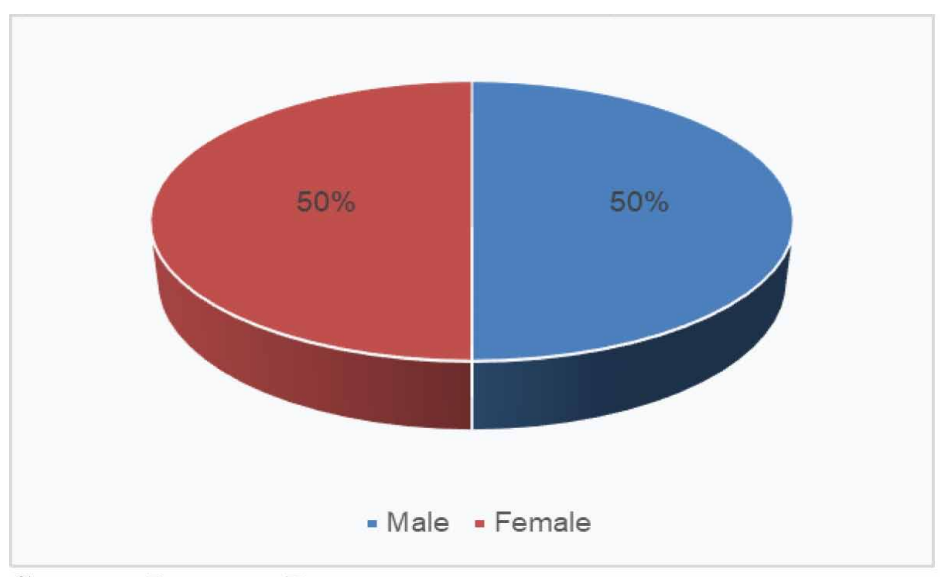

Source: Primary Data 


\subsection{Academic Qualifications}

Figure 4 suggested that the academic qualifications of the respondents are as follows: $65 \%$ of the respondents have bachelor's degrees, $25 \%$ have apprenticeship diplomas and $10 \%$ of the respondents have master's degrees. The results reflect that the respondents are educated enough to discharge their duties effectively and efficiently.

Figure 4. Academic qualifications

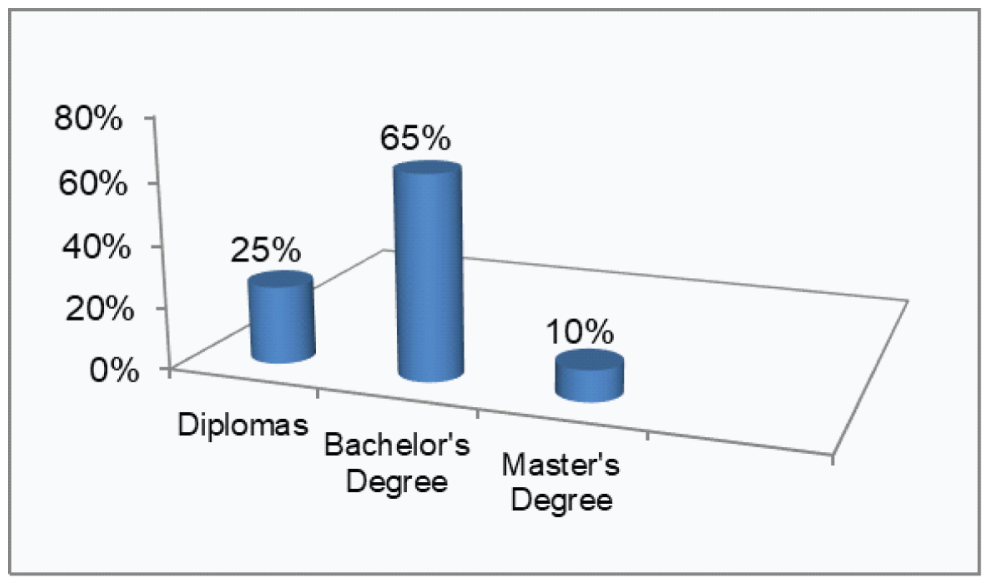

Source: Primary Data

\subsection{Work Period}

Figure 5 reflected that $30 \%$ of the respondents have served their organisations for a period of fewer than 2 years, while $43 \%$ have served for a period of 3 to 5 years, $22 \%$ have served between 6 to 9 years and $5 \%$ have served for 10 years and above. The results reflect that the employees are not staying in their organisations for a long period of time. Staff turnover is rife in these organisations.

\section{ANALYSIS AND DISCUSSION OF RESULTS}

\subsection{Regression Analysis}

Multiple Regression analysis was carried out on the factors that have an influence on employee retention. Table 3 reflects that the overall model with all the variables: job satisfaction, culture, work-life balance, remuneration, management, training and development, innovation, communication, rewards and recognition and succession planning have an influence on employee retention. The regression analysis reflects that .756 of the overall model in Table 3 is accounted for by the independent variables. The linear regression statistics are in support of the model at .756 . The $\mathrm{R}^{2}$ is .556 and the Adjusted $\mathrm{R}^{2}$ is .453.

Although the above statistical results have reflected that the independent variables are critical and significant, the prevailing situation in the Zimbabwean manufacturing industry needs a revamp for the industry to achieve employee retention.

\subsection{ANOVA Statistical Results}

ANOVA statistical tests were carried out as reflected on Table 4. The results reflected that there is a significant impact on employee retention as predicted by culture, work-life balance, remuneration, 
Figure 5. Work period

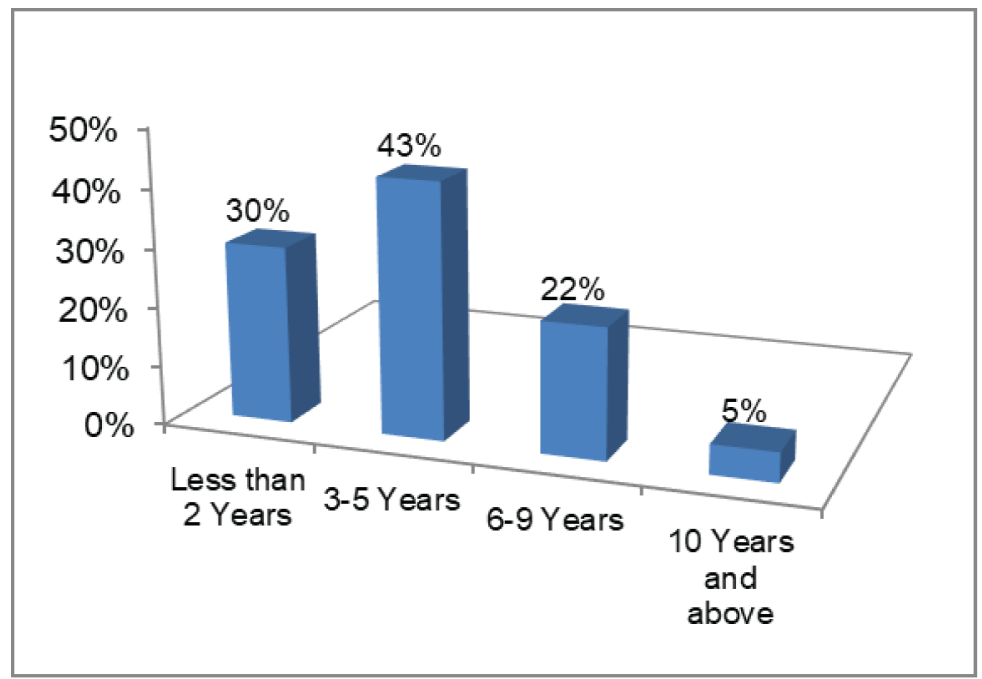

Source: Primary Data

Table 3. Regression analysis model

\begin{tabular}{|c|c|c|c|c|}
\hline Model & R & R Square & Adjusted R Square & $\begin{array}{c}\text { Std. Error of the } \\
\text { Estimate }\end{array}$ \\
\hline 1 & $.756^{\mathrm{a}}$ & .556 & .453 & .42776 \\
\hline
\end{tabular}

a. Predictors: (Constant), Retention, Regression, job satisfaction, work-life, remuneration, management, innovation, training and development, communication, rewards and recognition, succession planning.

Table 4. ANOVA

\begin{tabular}{|l|l|l|l|l|l|}
\hline \multicolumn{1}{|c|}{ Model } & \multicolumn{1}{c|}{ Sum of Squares } & \multicolumn{1}{c|}{ df } & Mean Square & F & Sig. \\
\hline Regression & 50.936 & 9 & .807 & 6.812 & .000 \\
Residual & 64.140 & 86 & & & \\
Total & 115.076 & 95 & & & \\
\hline
\end{tabular}

a. Dependent variable: Retention Culture

b. Predictors: (Constant), Culture Regression, job satisfaction, work life, remuneration, management, innovation, training and development, communication, rewards and recognition, succession planning.

management, innovation, training and development, communication, succession planning and rewards and recognition $(F(9,86)=6.812, p<.001)$.

The ANOVA statistical results reflected that the independent variables are significant and critical; however, the Zimbabwean manufacturing industry does not have much to offer. There is a need to ensure that the industry works towards putting into place as well as maintain the employee retention factors. 


\subsection{Job Satisfaction}

The results indicated that $80 \%$ of the respondents were not satisfied with their jobs, whilst $20 \%$ were satisfied with their jobs. This supports the fact that the employees are not satisfied and are leaving the organisations. The results reflect that there is a lot of improvement that is needed to enable the employees to be satisfied with their jobs.

Most of the employees are not satisfied with their jobs. Employees are motivated if their organisations offer acceptable working conditions, as well as a satisfying working atmosphere, realistic compensation and reasonable working conditions (Ul-Aabdeen, Khan, Tahir, Salman, Khan \& Ali, 2016). Job satisfaction drives employees to achieve much more beyond their expectations. Employees' good behaviour towards work is shaped by job satisfaction. Productive delays, absenteeism and turnover are usually triggered when the employees are not satisfied at work (Sila \& Sirok, 2018). A study conducted by James \& Mathew (2012) exposed that employee satisfaction, welfare benefits and organisational culture are the major factors that affect employee turnover. Effective implementation of employee retention strategies in the Zimbabwean manufacturing sector will ultimately enhance employee retention in the sector.

\subsection{Management and Leadership Decisions}

Management and leadership decision results reflected that $75 \%$ of the respondents were not satisfied with their management and leadership decisions, and only $25 \%$ were satisfied. The results however, reflected that management and leadership decisions caused the employees to leave the organisations. Management, leadership and supervision skills have a major role to play towards staff motivation.

Management and leadership decisions are critical. Most of the respondents are not satisfied with management and leadership decisions. Employees do not stay in an organisation when management lacks adequate leadership skills to support, guide and motivate the employees (Abdullah Al Mamun \& Hasan, 2017). A transparent relationship between the employee, supervisor and employer enhances the performance of the employee. It encourages the employee to be much more engaged and develops the skills and competency levels (Nasir \& Mahmood, 2018). The direction that the organisation takes motivates the employees to be committed to the organisation. Employees become loyal to the organisation when they see the future of the organisation.

\subsection{Training and Development}

Training and development is a tool that is used to motivate employees to stay in an organisation. The results suggested that $80 \%$ of the respondents indicated that they have never received training and development in the organisation, whilst only $20 \%$ indicated that they once received training a long time ago. There is a need to develop the employees if the organisations have to be successful.

Training and development of employees play an important role as it improves the skills of the employees for the current and future positions. Organisations are faced with technological changes as well as stiff competition. The Survival of the Zimbabwean manufacturing industries is based upon training and development of employees. Employees need to be trained and developed in tandem with current trends (Salah, 2016; Metha et al., 2014). Lack of training does not motivate the employees. Studies have reflected that career growth of the employees is pinned upon training and development (Ldama \& Bazza, 2015). The results obtained in another study confirm that comprehensive training and development is a strategy that employers can use to improve employee productivity (Oki, 2014).

\subsection{Rewards and Recognition}

Rewards and recognition are put in place to motivate the high achievers. The results indicated that $85 \%$ of the respondents were not satisfied with the rewards and recognition systems and that is why they are leaving their organisations, whilst only $15 \%$ indicated that they were satisfied. Rewards and recognition strategies help towards the retention of the employees. 
Rewards and recognition results are, however, not pleasing. It is important to ensure that rewards and recognition are used in order to avoid the dissatisfaction of employees which will encourage them to leave the organisation (Mngomezulu, Challenor, Munapo, Mashau \& Chikandiwa, 2015). Employees can be retained by giving them monetary rewards in the form of cash and allowances or it can be non-monetary recognition in the form of letters of appreciation (Nasir \& Mahmood, 2018). Rewards and recognition increase the morale of the employees, self-esteem as well as well-being and these are relevant strategies that organisations can use to avert staff turnover (Naseebullah \& Ahmad Shahrul Nizam, 2017). The Zimbabwean manufacturing sector can retain the employees by rewarding and recognising the efforts that the employees are putting in for the success of the sector.

\subsection{Fair Remuneration}

Fair remuneration results suggested that $85 \%$ of the respondents indicated that they were not happy with their remuneration, whilst only $15 \%$ indicated that they were content with their remuneration. The results reflect that there is no fair remuneration and as a result many employees are not satisfied and leave the industry.

Fair remuneration encourages the employee to remain at their organisation. The results obtained indicate that employees are not satisfied with the remuneration that they receive. High employee turnover is experienced due to the unfair remuneration that the employees are paid. Results from a study conducted by Calvin indicate that fair remuneration encourages the employees to remain at their organisation (Calvin, 2017). Some people have resigned from their jobs due to unsatisfactory compensating systems. Misaligned pay structures cause employee turnover. The compensation levels have an effect on staff retention in organisations (Bryant \& Allen, 2013).

\subsection{Work-Life Balance}

The work-life balance results indicated that $85 \%$ of the respondents are not satisfied with work-life balance, whilst only $15 \%$ of the respondents indicated that they were satisfied with work-life balance. There is a need to ensure that work-life balance is initiated and maintained in the organisations to promote a healthy workforce.

Most of the respondents are not satisfied with the work-life balance. Work-life balance is linked to an individual's performance, productivity and job satisfaction. A supportive work-life balance encourages a healthy work environment and balanced personal life, and this encourages employees to be loyal to the organisation they are working for (Garg \& Yajurvedi. 2016). A research by Sutanto $\&$ Kurniawan reflected that the quality of work-life leads to employee commitment which eventually translates to higher productivity and employee retention. A high attrition rate has a negative impact on service delivery and productivity (Chiboiwa et al., 2010). Studies carried out reflected that the attrition rate of employees is reduced by effective human resource practices which at the same time promote employee retention (Haider et al., 2015).

\subsection{Organisational Culture}

Organisational culture is very important in an organisation. The results suggested that $78 \%$ of the respondents are not happy with their organisational culture which they observe as weak, and only $22 \%$ indicated that they were satisfied with their organisational culture. Much needs to be done in order to develop organisational culture. Organisational culture is a critical variable that the organisations ought to have.

Culture provides an identity within the organisations and spells out what is expected of the employees to do. The results on organisational culture are not pleasing as most of the respondents were not satisfied with the organisational culture. Weak cultures are not ideal for the retention of employees. Culture is a true reflection of how members relate to each other as well as to stakeholders and customers (Madueke, \& Emerole, 2017). Organisational culture entails attitudes, habits and values 
that give the organisation the competitive edge. Culture plays a critical role towards employee job satisfaction (Kwakye, 2018).

\subsection{Innovation}

The results on innovation suggested that $75 \%$ of the respondents indicated that there is no room to be innovative in their organisation and $25 \%$ indicated that there is room for them to be innovative. The results obtained reflected that there is no room for innovation in the Zimbabwean manufacturing industry. Innovation is critical since it influences the performance of the employees.

Innovation comes through the implementation of employees' ideas concerning the development and improvement of new products and services. This will help to improve the organisation's competitive edge, administration processes, technological innovativeness and effective performance to enhance higher productivity (Osman, Shariff \& Lajin, 2016). Although change is imminent and is good, there are some employees who resist change. There is also a need to allow Generation X employees to develop themselves and be abreast with the advanced technological changes (Kesen, 2016).

\subsection{Succession Planning}

The results supported that there is no room for succession planning in most of the organisations according to $85 \%$ of the respondents and only $15 \%$ of the respondents indicated that there is succession planning in their organisations.

The results reflected that there is no room for succession planning, and this is not a healthy situation for organisational growth and continuity. The Zimbabwean manufacturing industry is not flourishing due to lack of succession planning. Competent staffs leave the industry because there is no motivation for future positions. Succession planning is a systematic endeavour by an organisation to ensure that leadership in strategic key positions is mentored and developed for the sake of continuity. It is essential to have succession planning. This encourages staff retention and intellectual development of key personnel. Individual advancement is also achieved. Maintenance and preservation of the knowledge capital base is achieved in the organisation (Maphisa, Zwane \& Nyide, 2017).

\subsection{Effective Communication}

Effective communication is lacking in the organisations, $79 \%$ of the respondents indicated that there is no effective communication and $21 \%$ of the respondents indicated that there is effective communication. Lack of effective communication results in poor performance of the organisations hence, this has a negative effect on the performance of the organisations and the industry as a whole.

The results reflected that there is no effective communication and this adversely affects organisational operations. Effective communication facilitates trust, frankness and helps the employees to identify with the organisation. Communication pertaining to the organisation and communication between strategic business units and management has a strong effect on employee retention. Employees' loyalty increases when employees become a part of the organisation's decision making processes (Dutta \& Banerjee, 2014). Effective communication in organisations leads to collective commitment, employee engagement, collective commitment and employees will end up being satisfied with their jobs. This will eventually lead to a high level of employee retention (Newman, 2017). A study by Cloutier reflects that effective communication necessitates the retention of employees (Cloutier et al., 2015).

\section{RECOMMENDATIONS}

Due to the challenges that the Zimbabwean manufacturing companies are going through this paper recommends that: 
- An effective manufacturing sustenance strategy model fit to revamp the Zimbabwean manufacturing industry, as well as resuscitate the retention of employees needs to be put in place. Once the productivity capacity increases it becomes easy to offer the employees attractive welfare benefits meant to retain the skilled and talented personnel within the manufacturing sector in Zimbabwe;

- Effective human resource processes and practices help to reduce the employees' attrition rate and promote employee retention within the sector;

- Effective managerial and supervision skills need to be cultivated to enable staff motivation and retention;

- The respective management should put in place management and leadership strategies that can help to motivate and retain employees since employee retention is critical if organisations have to succeed;

- There is a need for the organisations to ensure that they put effective remuneration and recognition systems in order to retain talent and avoid employee turnover;

- There is a need for institutions to train and develop their staff, since the organisations' human resource base is the organisations' main assets;

- Effective communication in every organisation is essential. It helps to create a good relationship between the workers and management. Effective communication channels should be created in order to have a good flow of communication between the employees and the management;

- Management needs to employ good leadership skills in order to curb staff turnover. Leadership training and development is also needed to equip the management; and

- Staff retention strategies should be incorporated in the strategic plans of the organisations to ensure that resources are mobilised to attend to the crucial issues of addressing the staff turnover in the organisations.

\section{CONCLUSION}

From the discussions presented, the key findings have reflected that the employees are not satisfied with their jobs. The Zimbabwean manufacturing firms are performing below capacity and this makes it difficult for them to retain skilled employees. Lack of appropriate rewarding systems and recognition, work-life balance, inadequate training and development opportunities, lack of effective communication, lack of effective management and leadership decisions, lack of innovation and lack of succession planning are the major factors that lead to employee turnover in the Zimbabwean manufacturing sector. Employees are in need of job satisfaction, a good working environment, effective and efficient leadership, attractive remuneration, fringe benefits, job fit and career development. Employees become committed to their work and the organisation if these factors are addressed. Most of the employees leave for the South African labour market, where the industries are performing well and there is a constant demand for skilled workers. The limitation of this paper is that it concentrated on the Zimbabwean manufacturing sector only and did not delve into other sectors of the economy. Further research can be widened to incorporate the other sectors of the economy with a larger population and sample sizes and different research methodologies. 


\section{REFERENCES}

Adeoye, A. O., \& Fields, Z. (2014). Compensation Management and Employee Job Satisfaction: A Case of Nigeria. School of Management. Information Technology and Governance., 4(3), 345-352.

Ahmed, G. (2014). McGregor Theory X and Theory Y for Staff and Employees Motivation. Available: http:// www.studylecturenotes.com/management/mcgregor-theory-X-and-theory-y-for-staff-and-employees-motivation

Akinyomi, O. J. (2016). Labour Turnover: Causes, Consequences and Prevention. Fountain University Journal of Management and Social Sciences., 5(1), 105-112.

Al Mamun, A. C., \& Hasan, N. (2017). Factors affecting employee turnover and sound retention strategies in business organization: A conceptual view. Problems and Perspectives in Management, 15(1), 63-71. doi:10.21511/ ppm.15(1).2017.06

Arokiasamy, A. R. A. (2013). A Qualitative Study on Causes and Effects of Employee Turnover in the Private Sector in Malaysia. Middle East Journal of Scientific Research, 16(11), 1532-1541.

Aruna, M., \& Anitha, J. (2015). Employee Retention Enablers: Generation Y Employees. SCMS Journal of Indian Management., 12(3), 94.

Azeez, S. A. (2017). Human Resource Management Practices and Employee Retention. Journal of Economics. Management and Trade., 18(2), 1-10.

Bajpai, N., Prasad, A., \& Pandey, P. N. (2016). Work Life Balance Retention (WLBR) Model - A Weapon too. IJCEM International Journal of Computational Engineering \& Management., 16(5), 27-30.

Balamurugan, G., \& Abinaya, R. (2016). A Study on Employee Retention Strategies in Leading IT Companies at Trichy. Intercontinental Journal of Human Resource Research Review., 4(3), 42-48.

Balamurugan, G., \& Pasupathi, P. (2018). A study on the effect of work-life balance on productivity. International Journal of Emerging Research \& Development., 1(7), 1-4.

Bryant, P. C., \& Allen, D. G. (2013). Compensation, Benefits and Employee Turnover: HR Strategies for Retaining Top Talent. Compensation and Benefits Review, 45(3), 171-175. doi:10.1177/0886368713494342

Calvin, O. Y. (2017). The impact of remuneration on employee's performance. Arabian Journal of Business and Management Review., 4(2), 34-43.

Cheema, F. E. A., Shujaat, S., \& Alam, R. (2013). Impact of Non-monetary Rewards on Employees' Motivation: A Study of Commercial Banks in Karachi. Journal of Management and Social Sciences., 9(2), 23-30.

Chen, M. (2014). The Effect of Training on Employee Retention. International Conference on Global Economy, Commerce and Service Science, 1(1), 356-359. doi:10.2991/gecss-14.2014.90

Chiboiwa, M. W., Samuel, M. O., \& Chipunza, C. (2010). An examination of employee retention strategy in a private organisation in Zimbabwe. African Journal of Business Management, 4(10), 2103-2109.

Cloutier, O., Felusiak, L., Hill, C., \& Pemberton-Jones, E. J. (2015). The Importance of Developing Strategies for Employee Retention. Journal of Leadership, Accountability and Ethics, 12(2).

Dalluay, V., Jalagat, R., Zadjali, A. K. H. A., \& Al-Abdullah, A. (2017). The Impacts of Job Satisfaction on Employee Turnover: A Case Study of Oman Air in the Sultanate of Oman. European Academic Research, 5(1), $331-374$.

Dutta, A. B., \& Banerjee, S. (2014). Study of employee retention. International Journal of Business Management \& Research, 4(1), 83-88.

Fitzgerald, M. (2014). Talent and Talent Management Insights. Available: https://eoeleadership.hee.nhs.uk/sites/ default/files/Insight-1-Defining-Talent-and-Talent-Management.pdf

Garg, P., \& Yajurvedi, N. (2016). Impact of Work-Life Balance Practices on Employees Retention and Organizational Performance - A Study on IT Industry. Indian Journal of Applied Research, 6(8), 105-108. 
Habiyaremye, A. (2020). Fast tracking the SADC integration agenda to unlock regional collaboration gains along growth corridors in Southern Africa. WIDER Working Paper 2020/95. United Nations University World Institute for Economics Development Research. 10.35188/UNU-WIDER/2020/852-8

Haider, M., Rasli, A., Akhtar, C. S., Yusoff, R. B. M., Malik, O. M., Aamir, A., \& Tariq, F. et al. (2015). The impact of human resource practices on employee retention in the telecom sector. International Journal of Economics and Financial Issues, 5(1S), 63-69.

IFAD. (2016). 'Fostering Inclusive Rural Transformation'. Rural Development Report 2016. International Fund for Agricultural Development.

Iqbal, S., Guohao, L., \& Akhtar, S. (2017). Effects of Job Organizational Culture, Benefits, Salary on Job Satisfaction Ultimately Affecting Employee Retention. Review of Public Administration and Management., 5(3), 2-7. doi:10.4172/2315-7844.1000229

Jalagat, R. (2016). Job Performance, Job Satisfaction, and Motivation: A Critical Review of their Relationship. International Journal of Advances in Management and Economics., 5(6), 36-42.

James, L., \& Mathew, L. (2012). Employee Retention Strategies: IT Industry. SCMS Journal of Indian Management, 9(3).

Kaur, R. (2017). Employee Retention Models and Factors Affecting Employees Retention in IT Companies. International Journal of Business Administration and Management., 7(1), 161-174.

Kesen, M. (2016). The Impact of Employee Training and Innovation on. International Journal of Academic Research in Business \& Social Sciences, 6(1), 174-185. doi:10.6007/IJARBSS/v6-i1/1987

Kossivi, B., Xu, M., \& Kalgora, B. (2016). Study on Determining Factors of Employee Retention. Open Journal of Social Sciences., 4(1), 261-268. doi:10.4236/jss.2016.45029

Kwakye, E. O. (2018). Organisational Culture and Employee Turnover: Journal of Economics. Management and Trade., 21(2), 1-11.

Ldama, J., \& Bazza, M. I. (2015). Effect of Training and Development on Employees' Retention in Selected Commercial Banks in Adamawa State-Nigeria. European Journal of Business and Management, 7(36), 96-101.

Madueke, C. V. (2017). Organizational Culture and Employee Retention of Selected Commercial Banks in Anambra State. Saudi Journal of Business and Management Studies., 2(3B), 244-252.

Mahan, T., Nelms, D., \& Bearden, C. (2018). 2018 Retention Report Truth \& Trends inTurnover. Available:https:// cdn2.hubspot.net/hubfs/478187/2018\%20Retention\%20Report/Work\%20Institute\%202018\%20Retention\%20 Report\%20043018\%20-\%20Final.pdf

Maphisa, S. B., Zwane, B. K., \& Nyide, C. J. (2017). Succession Planning and Staff Retention Challengers: An industrial Outlook and Major Risks. Risk Governance \& Control. Financial Markets \& Institutions., 7(3), 17-26.

Mathimaran, K. B., \& Kumar, A. A. (2017). Employee Retention Strategies - An Empirical Research. Global Journal of Management and Business Research, 17(1), 16-22.

Mbugua, G. M., Waiganjo, E. W., \& Njeru, A. (2016). Relationship between Strategic Performance Management and Employee. International Journal of Business Administration, 6(1), 53-62.

Metha, M., Kurbetti, A., \& Dhankhar, A. (2014). Study on Employee Retention and Commitment. International Journal of Advance Research in Computer Science and Management Studies., 2(2), 154-164.

Mishra, P. K. (2013). Job Satisfaction. IOSR Journal of Humanities and Social Science., 14(5), 45-54. doi:10.9790/1959-1454554 PMID:24035566

Mngomezulu, N., Challenor, M., Elias, M. E., Mashau, P., \& Chikandiwa, C. T. (2015). The impact of recognition on retention of good talent in the workforce. Journal of Governance and Regulation., 4(4), 372-379. doi:10.22495/ jgr_v4_i4_c3_p2

Motlou, R. G., Singh, S., \& Karodia, A. M. (2016). An Evaluation of the Impact of Job Satisfaction on Employee Retention at Lonmin Rowland Shaft North West Province. Kuwait Chapter of Arabian Journal of Business and Management Review., 5(10), 15-49. doi:10.12816/0027366 
Naseebullah, L., \& Ahmad Shahrul Nizam, I. (2017). Impact of Rewards and Recognition on Malaysian IT Executives Well-being and Turnover Intention: A Conceptual Framework. Global Business and Management Research, 9(1), 153-161.

Nasir, S. Z., \& Mahmood, N. (2018). A Study of Effect of Employee Retention on Organizational Competence. International Journal of Academic Research in Business \& Social Sciences, 8(4), 408-415. doi:10.6007/ IJARBSS/v8-i4/4022

Newman, J. (2017). 7 Tips for Better Employee Retention. Available: https://static1.squarespace.com/ static/558d6d83e4b06cd18ce2208a/t/5a13187653450a4d992b8747/1511200886542/7+tips+for+better+emp loyee+retention\%27.pdf

Ngarachu, A., Wood, C., Krogman, H., Tshuma, E., Mudenda, D., \& Grant Makokera, C. (2018). Border Economies. Global Economic Governance Discussion Paper, November. Pretoria: GEG.

Nwagbara, U., Oruh, E. S., Ugorji, C., \& Ennsra, M. (2013). The Impact of Effective Communication on Employee Turnover Intension at First Bank of Nigeria. Economic Insights - Trends and Challenges, 2(4), 13-21.

Nwokocha, I., \& Iheriohanma, E. B. J. (2012). Emerging Trends in Employee Retention Strategies in a Globalizing Economy: Nigeria in Focus. Asian Social Science, 8(10), 198-207. doi:10.5539/ass.v8n10p198

Oki, E. U. (2014). The Impact of Employee Retention on Customer Satisfaction in the Nigerian Service Organizations (A Study of Some Selected Hotels in JOS, Plateau State). International Journal of Managerial Studies and Research., 2(9), 140-154.

Ongori, H. (2007). A review of the literature on employee turnover. African Journal of Business Management, $1(1), 49-54$.

Osman, S., Shariff, A. H., \& Lajin, M. N. A. (2016). Does Innovation Contribute to Employee Performance? Procedia: Social and Behavioral Sciences, 219(1), 571-579. doi:10.1016/j.sbspro.2016.05.036

Rijamampianina, R. (2015). Employee turnover rate and organizational performance in South Africa. Problems and Perspectives in Management, 13(4), 240-253.

SADC. (2019). SADC Selected Economic and Social Indicators. SADC Secretariat.

Salah, M. R. A. (2016). The Impact of Training and Development on Employees Performance and Productivity. International Journal of Management Sciences and Business Research., 5(7), 36-70.

Sandhya, K., \& Kumar, D. P. (2011). Employee retention by motivation. Indian Journal of Science and Technology, 4(12), 1778-1782. doi:10.17485/ijst/2011/v4i12.34

Shakeel, N., \& But, S. (2015). Factors Influencing Employee Retention: An Integrated Perspective. Journal of Resources Development and Management., 6(1), 32-50.

SHRM \&Globoforce. (2018). Using Recognition and Other Workplace Efforts to Engage Employees. Available:https://www.shrm.org/hr-today/trends-and-forecasting/researchandsurveys/Documents/

SHRMGloboforceEmployeeRecognition\%202018.pdf

Sila, E., \& Sirok, K. (2018). The Importance of Employee Satisfaction: A Case Study of a Transportation and Logistics Service Company. Management, 13(2), 111-136. doi:10.26493/1854-4231.13.111-136

Singh, K. S., \& Jain, M. (2013). Study of employee's job satisfaction and its impact on their performance. Journal of Indian Research, 1(4), 105-111.

Sutanto, E. M., \& Kurniawan, M. (2016). The impact of recruitment, employee retention and labor relations to employee performance on batik industry in Solo City, Indonesia. International Journal of Business and Society, 17(2). Advance online publication. doi:10.33736/ijbs.531.2016

Uitzinger, D., Chrysler-fox, P., \& Thomas, A. (2018). Perceptions of human resource professionals of. Independent Research Journal in the Management Sciences., 18(1), 1-10.

Ul-Aabdeen, Z., Khan, M. N., Tahir, M., Salman, M., Khan, H. G. M., \& Ali, K. (2016). Employee Satisfaction and Its Impact on Job Turnover. International Journal of Economics and Business Administration., 2(4), 21-26. 
Wong, N. Z. Y., \& Chin, Y. F. (2016). Issues and Challenges Faced by Generation X While Managing Generation Y. International Journal of Business and Social Science, 7(2), 167-170.

Woods, S. A., \& West, M. A. (2015). The Psychology of Work and Organizations (2nd ed.). Cengage Learning EMEA.

World Bank. (2019). Belt and Road Economics: Opportunities and Risks of Transport Corridors. The World Bank.

Zhang, Y. (2016). A Review of Employee Turnover Influence Factor and Countermeasure. Journal of Human Resource and Sustainability Studies, 4(1), 85-91. doi:10.4236/jhrss.2016.42010 